\title{
Ethnographie Des Pratiques De Sécurisation De L'accès Aux Ressources Agropastorales Dans Un Contexte De Conflits Entre Agriculteurs Et Migrants Eleveurs A Dianra (Côte d'Ivoire)
}

\author{
Kouame Konan Jacques \\ Doctorant en Sociologie, \\ Université Alassane Ouattara de Bouaké (Côte d’Ivoire)
}

doi: 10.19044/esj.2016.v12n8p298 URL:http://dx.doi.org/10.19044/esj.2016.v12n8p298

\begin{abstract}
Climate variability and dwindling agro-pastoral resources are considered a threat to the stability of nations. Their environmental, economic, social and policies consequences on people behind this threat. The conflict farmers and ranchers is one of the consequences. In the northern Ivory Coast in general and in particular Dianra, the conflict between farmers and herders is not new. It is recurrent and sometimes violent. In this context of conflict and dwindling resources, one of the challenges is access to agropastoral resources, because despite these conflicts, indigenous farmers and migrant herders always co-operate the same space. There have been many writings on conflict farmers and ranchers. They aimed to understand the causes. In this study, our interest is less conflict. But the analysis we make is, how in the context of conflict, the user groups manage to secure access to resources. The study, conducted with fifty four (54) persons shows that in this context of conflict, access to resources is part of a dynamic interaction mobilizing various strategies to control and maintain access to resources: change of rules by the institutions of the dynamic layout, arrangements, handling of identity or professional referral and multiple use. If people develop coping strategies to different challenges offered by the changing context of their environment, it should be noted that these strategies highlight the social values of current changes in this environment.
\end{abstract}

Keywords: Climate change, migration, conflict, access to resources, strategic

\section{Résumé}

Les variabilités climatiques et l'amenuisement des ressources agropastorales sont considérées comme une menace pour la stabilité des 
nations. Leurs conséquences environnementales, économiques, sociales et politiques sur les populations expliquent cette menace. Le conflit agriculteurs et éleveurs est l'une des conséquences. Dans le nord ivoirien en général et en particulier à Dianra, le conflit entre agriculteurs et éleveurs n’est plus un fait nouveau. Celui-ci est récurrent et parfois violent. Dans ce contexte de conflit et d'amenuisement des ressources, l'un des enjeux est l'accès aux ressources agropastorales, car en dépit de ces conflits, les autochtones agriculteurs et migrants éleveurs co-exploitent toujours le même espace. Il y a eu de nombreux écrits sur les conflits agriculteurs et éleveurs. Ils ont eu pour objectif de comprendre les causes. Dans cette étude, ce qui nous intéresse est moins les conflits. Mais, l'analyse que nous en faisons est, comment dans ce contexte conflictuel, les groupes d'utilisateurs parviennent à se garantir un accès aux ressources. Cette étude, menée auprès de cinquante quatre (54) personnes montre que dans ce contexte de conflit, l'accès aux ressources s’inscrit dans une dynamique d'interaction mobilisant des stratégies diverses de contrôle et de maintien de l'accès aux ressources : changement des règles du jeu par la mise en dynamique des institutions, des arrangements, la manipulation de l'identité ou du référent professionnel et la pluralité de recours. Si les populations développent des stratégies d'ajustement aux différents enjeux qu'offre le contexte changeant de leur environnement, il faut noter que ces stratégies mettent en exergue des mutations de valeurs sociales en cours dans ce milieu.

Mots clés : Changement climatique, migration, conflit, accès aux ressources, stratégies

\section{Introduction}

Le département de Dianra est traditionnellement une zone agricole. Les cultures vivrières et le coton étaient les activités des populations. Mais, la crise du coton et la dégradation des conditions socio économiques ont amené les autochtones sénoufo et malinké à adopter des stratégies de conversion. Le paysage agricole va ainsi connaître une modification avec le développement de la culture d'anacarde substituée aux autres cultures existantes. Il faut dire que devant la dégradation de la situation socio économique des populations rurales, on assiste souvent à des phénomènes de conversion. Mais, la modification du paysage agricole de Dianra ne s'est pas limitée à la culture de l'anacarde. Dianra est devenu en effet au fil des années une zone d'accueil de migrants éleveurs à la recherche de pâturage. Dans cet espace agropastoral, les conflits entre agriculteurs et éleveurs ont émergé et sont inhérents à la vie quotidienne des populations. Les deux activités (agricoles et élevage) sont dans une dynamique d’évolution: évolution des catégories d'éleveurs, du nombre de cheptel et des pratiques agricoles. Or, 
Dianra semble de plus en plus confronté à l'échelle du terroir, à l'amenuisement progressif des terres agricoles et des pâturages.

Ce manque à gagner conjugué à l'absence d'évolution favorable des rapports d'exploitation des ressources naturelles, a perturbé les systèmes de production ainsi que les rapports entre agriculteurs et éleveurs. Les conflits entre agriculteurs et éleveurs sont devenus fréquents et se sont traduits par des affrontements violents. Ils se sont soldés par des dégâts matériels, des pertes en vie humaine ou par des emprisonnements. Par exemple, à Yérétiélé, cent neuf (109) bœufs ont été tués par les populations locales. À Solifiro des paysans ont fait cinq (5) mois de prison à Séguéla. Le chef du village de Tchinvolokaha a été emprisonné à Bouaké comme l’atteste cet agriculteur C.K :

"le chef du village nous donnait l'ordre d'aller chasser les peuls autour de nos champs, celui qui ne veut pas partir, on le frappait et on attrapait certains de ses boufs pour venir attacher. Quant ils viennent, on discute avec eux, avant de lui donner les boufs pour qu'ils partent. Nous avons procédé comme ça, jusqu'à ce qu'on vienne arrêter notre chef du village pour aller l'emprisonner à Bouaké » (Extrait d'entretien réalisé avec C.K le 11/04/2012 à Tchinvolokaha)

Ces conflits autour des ressources qui elles-mêmes se raréfient sont susceptibles de compromettre l'accès et l'exploitation des ressources. Il se pose alors dans ce contexte conflictuel, la question de l'accès aux ressources. Car, les autochtones agriculteurs et migrants éleveurs co-exploitent toujours le même espace. L'étude se situe dans une problématique de l'accès aux ressources dans un contexte de changement climatique, d'amenuisement et de conflits d'usage des ressources. Elle s'interroge sur la manière dont les uns et les autres agissent pour se garantir un accès aux ressources. Cette question trouve sa pertinence dans l'examen des modes de régulation et d'accès aux ressources pastorales des migrants éleveurs.

\section{Objectifs de l'étude}

La préoccupation première de cette étude est de comprendre les pratiques de sécurisation de l'accès aux ressources agropastorales dans un contexte de conflits d'usage exacerbés, étant donné que leur capacité de subsistance en dépend.

L'hypothèse que nous défendons ici est que: face aux enjeux de l'accès et de l'exploitation des ressources agropastorales dans un contexte de conflit, les agriculteurs et éleveurs empruntent des itinéraires de sécurisation à travers lesquels ils mobilisent entre autre les institutions comme ressources. 


\section{Matériels et méthode}

Pour traiter les questions posées ci-dessus, nous avons adopté une approche ethnographique des faits. L’approche ethnographique consiste en une description fine, contextuelle et transversale des faits tels qu'ils se déroulent localement. L'ethnographie des conditions d'accès, des stratégies et des interactions des acteurs autour de l'accès aux ressources, consiste à décrire, pour un groupe d'acteurs ou d'utilisateurs (populations autochtones et migrants éleveurs) l'ensemble de sa manière de faire et d'agir à propos de l'accès aux ressources dans ce contexte de conflit.

\section{Les outils de collecte de données}

L’approche adoptée étant essentiellement qualitative, la collecte des données s'est faite à l'aide des techniques suivantes: l'entretien semi directif, le récit de vie de l’histoire environnementale.

\section{Echantillonnage}

Cette étude s'est appuyée sur un échantillon de village du département de Dianra. Le choix de ces villages s’est fait sur la base de leur fragilité au conflit et, de leur situation en fonction de l'itinéraire des migrants éleveurs. Les villages Yérétiélé, Lenguédougou et Tienvolokaha sont des portes d'entrée des éleveurs et sont fragiles au conflit. Yérétiélé est reconnu par les populations locales et même par les éleveurs comme un village où les conflits sont récurrents à cause du barrage qui s’y trouve. Tomikro, Pétérikaha constituent les portes de sortie des transhumants vers les départements de Mankono, Kani etc. Mais, cette sortie ne se fait pas sans tension. Les personnes interrogées sont: les populations autochtones (agriculteurs) et les migrants éleveurs. Le principe de saturation ((pires, 1997) a permis de constituer l'échantillon. Cinquante quatre (54) personnes ont été ainsi interviewées (voir tableau ci-dessous).

Tableau : répartition de l'échantillon

\begin{tabular}{|c|c|c|}
\hline $\begin{array}{c}\text { Groupes cibles } \\
\text { de l'étude }\end{array}$ & Qualité/statut & $\begin{array}{c}\text { Nombre } \\
\text { d'enquêtés }\end{array}$ \\
\hline \multirow{3}{*}{$\begin{array}{c}\text { Populations } \\
\text { autochtones }\end{array}$} & Chefs de village/notables & 5 \\
\cline { 2 - 3 } & $\begin{array}{c}\text { Responsables de comité } \\
\text { Villageois de règlement de conflit }\end{array}$ & 10 \\
\cline { 2 - 3 } & Chefs de terre & 4 \\
\cline { 2 - 3 } & Paysans & 16 \\
\cline { 2 - 3 } & Responsables association agricole & 2 \\
\hline Migrants éleveurs & Responsables associations d'éleveurs & 10 \\
\cline { 2 - 3 } & Sédentaires & 4 \\
\cline { 2 - 3 } & transhumants & $\mathbf{5 4}$ \\
\hline
\end{tabular}




\section{Méthode d'analyse des données}

Le caractère qualitatif de l'étude nous a amené à opter pour une analyse de contenu manuelle de nos données. Il s’est agit de décrire le contenu de nos entretiens et de l'interpréter. Les entretiens ont d'abord été transcris avant de constituer un support d’analyse. Ainsi, les catégories analytiques ont été conçues. Ce sont les éléments du discours de même nature, du même ordre ou du même registre ou des expressions, des concepts tous faits provenant des enquêtés. En d'autres termes, il s'est agi de regrouper les réponses des enquêtés en fonction des similitudes et par rapport aux objectifs de l'étude. Ainsi, les différents thèmes de nos guides d'entretien et les récurrences des réponses ont permis d'établir les catégories d'analyse qui sont les suivantes: le mode et les règles d'accès aux ressources, les stratégies des acteurs, les ressources investies, les rapports de pouvoirs, le profil des éleveurs. Les concepts présentés par la sociologie des organisations (Crozier et Friedberg, 1977 ; Friedberg, 1993) sont sur lesquels s’est appuyée l'interprétation des données. Ceci pour mettre en évidence dans le discours des acteurs, les éléments rendant compte des interactions, des stratégies et jeux (de pouvoir) qu’ils mettent en œuvre.

\section{Résultats}

Les résultats sont présentés en quatre parties. La première partie a trait à la caractérisation de l'espace agropastoral de Dianra, la deuxième partie présente le conflit entre agriculteurs et éleveurs. Elle présente d’abord les acteurs en conflits avec leur atout, la manifestation du conflit et leurs motifs. La troisième présente les enjeux liés à la pratique de l'élevage et à l'exploitation des ressources. La quatrième et la dernière partie décrit les interactions des acteurs dans l'accès aux ressources.

\section{Caractérisation de l'espace agropastoral de Dianra}

Le département de Dianra est situé au nord de la Côte d’Ivoire. Il est limité au nord par celui de Boundiali, au sud par le département de Séguéla et celui de Mankono, à l'Est par le département de Korhogo et, à l’Ouest par celui de Kani. L’espace agropastoral désigne l'unité spatiale utilisée pour pratiquer à bien l'activité agricole et pastorale. Il contient des ressources agricoles et pastorales pouvant être exploitées pour celles-ci. L'espace pastoral selon César (1992, cité par Béchir, 2010 : 128), est la totalité des terres parcourues par le bétail dans le but d’y prélever sa nourriture.

Dans la zone de Dianra, l'espace reste dévolu à l'activité agricole (cultures vivrières, la culture du coton et celle de l'anacarde). Parlant d'espace pastoral à l'intérieur des terroirs villageois, il n'existe pas d'espace pastoral exclusif. De manière générale, dans les textes législatifs ivoiriens, il n’existe pas de régime foncier pastoral. En d'autres termes, il n’existe aucun 
texte reconnaissant l'activité pastorale comme une mise en valeur des terres et donnant aux éleveurs un droit d'usage exclusif de l'espace. L'espace pastoral change en fonction des terres cultivées. Aussi, l'espace est caractérisé par l'absence de piste à bétail formellement reconnue. Les pistes à bétail sont informelles et changent au fil des années en fonction de la mise en cultures des espaces de parcours.

Dianra: une zone confrontée aux effets de la variabilité climatique et à l'amenuisement des ressources agropastorales

Les populations interrogées sur l'état actuel de leurs ressources, sont unanimes sur le changement observé de leur environnement. Elles perçoivent les effets du changement climatique par le «manque de pluie», le tarissement des cours d'eau, l'appauvrissement des sols et par une saison sèche très longue accompagnée de soleil de plus en plus ardent. Disons que la pluviométrie annuelle dans le département de Dianra oscille entre 1200 à 1400 mm avant les années 1970. Après les années 1970, la pluviométrie a connu une baisse. Elle se situe entre 1000 et $1200 \mathrm{~mm}$. Soit une baisse de 200 à 400 mm. En outre, selon les populations, il faut cultiver aujourd'hui de grande superficie pour avoir assez de produits agricoles. Ce qui est contraire d'autrefois. Quant à la disponibilité des ressources, ils affirment que les terres agricoles sont devenues de plus en plus rares et le pâturage naturel connaît un rétrécissement continu. Les populations justifient l'amenuisement des ressources (terres agricoles, pâturages) par l'augmentation de la population, l'usage de la traction animale et du développement de la culture d'anacarde. L'adoption de la traction animale conjuguée à l'augmentation de la population a entrainé et entraîne l'extension des terres cultivées. Cette extension est exacerbée avec la culture d'anacarde. Les vergers ont une superficie comprise entre 13 et 23 ha à Dianra selon les données du PNIA. Les effets de la variabilité climatique sur les productions vivrières ainsi que sur les revenus agricoles justifient chez les populations l'essor de cette culture dans le Nord en général et à Dianra en particulier. L’adoption de la culture d'anacarde répond donc à une logique de diversification de revenu. L'anacarde est pour les populations du Nord ce qu'est le cacao ou le café à l'Ouest. Avec la culture d'anacarde, les jachères servant de pâturage sont en raréfaction. Nos assertions sont soutenues par les propos suivants :

«... avant il y avait l'eau à tout moment dans le fleuve FOMBOU, l'eau ne manquait même pas là-bas, et aussi, il y avait assez de pâturage. Autrefois, il y avait des zones, où il n'existait pas de champ sur des kilomètres, mais actuellement les champs sont devenus très grands et extensifs à cause de l'anacarde, et la population a augmenté aussi, on n'est devenu nombreux » (Extrait de l'entretien réalisé avec K.N le 01 Mai 2012 à Solifono).

Un espace caractérisé par l'absence de pistes à bétail formelle 
Nous avons relevé une absence de piste à bétail formellement reconnue. En fait, les troupeaux doivent emprunter des pistes à bétail afin d'éviter toute divagation des troupeaux dans les champs de culture. Les pistes à bétail sont des voies empruntées pour l'acheminement du bétail des zones d'élevage vers les zones de transhumance ou d'autres zones de production et même les centres de commercialisation. Il faut dire que les pistes à bétail sont informelles et changent au fil des années en fonction de la mise en cultures des espaces de parcours. Etant donné qu'il n’y a pas d'espace pastoral exclusif, les deux activités (agricultures et élevage) cohabitent obligatoirement sur le même espace.

\section{Le conflit autochtones (agriculteurs) et migrants éleveurs}

L'un des constats majeurs frappant tout observateur s'intéressant aux conflits entre agriculteurs et éleveurs à Dianra, est la présence de nombreuses tensions et des conflits liés à l'accès et l'exploitation des ressources. Nous avons relevé deux catégories de conflits: à savoir les conflits liés à l'accès aux ressources et ceux liés au manquement des normes sociales.

Les conflits liés à l'accès aux ressources

Les confits liés à l'accès aux ressources partent de dégâts de cultures et de désaccord sur les pistes à bétail. Les dégâts de cultures (maïs, riz, igname, coton, anacarde, maraîchères) par les bœufs sont des coûts supplémentaires dans l'activité agricole. Avec le développement de l'anacarde, il n'y a plus de période libre pour l'activité de l'élevage sans dégât de cultures, comme dans le passé. Car, la période de la noix d'acajou coïncide avec celle de la transhumance. Ce qui rend quotidien les conflits. Selon les parties en conflit, les dégâts de cultures s'expliquent par l'amenuisement des terrains de parcours et les espaces de pâturage; conséquence de l'extension des terres cultivées surtout avec l'essor de la culture d'anacarde et de l'augmentation de la population locale. Les propos de cet éleveur l'attestent bien :

«Ce sont les causes de nos conflits, les conflits en réalité, les conflits viennent de là, un d'abord il n'ya plus d'espace, les éleveurs ne sont pas considérés parce que on passe habituellement avec les boufs quelqu'un s'en va mettre son champ là-bas les bœufs ne peuvent plus atteindre l'eau où il faut aller boire, donc les bøufs sont obligés de passer pour aller vers le fleuve pour aller boire ou vers le barrage pour aller boire. Au bord du barrage vous prenez exemple sur le barrage de Dianra aujourd'hui tout l'entourage est cultivé, tout aux alentours il n'ya pas une seule entrée pour dire que c'est là ils ont laissé pour que les bœufs puissent boire. Donc comme cela comment, on peut diminuer les dégâts, tous les espaces aussi ce sont les champs 
d'anacarde, il n'ya plus d'espace ». (Extrait d'entretien réalisé avec K.S. agro-éleveur, le 13 Mai 2012 à Dianra S/P)

Mais, les conflits ne découlent pas directement des dégâts. D’autres raisons secondaires transforment les tensions en conflits ouverts. Elles se présentent comme suit : l'identification de l'auteur des dégâts, le non respect du délai de paiement du montant d'indemnisation et la justice par l'équilibre des préjudices. En effet, lorsqu'il y a un dégât de culture et l'auteur n’a pas été pris avec les bœufs dans le champ, il devient difficile de trouver le vrai coupable. Et si par aventure un bouvier errant dans les environs avec ses bœufs, celui-ci est automatiquement accusé. Celui-ci refusant de reconnaître les faits, les discussions aboutissent souvent à des actes de violence ou à des conflits ouverts. En plus, il arrive parfois que l'éleveur ne respecte pas le délai de paiement, ou ne paye plus le reste du montant après avoir effectué un premier versement. Frustrés, les paysans se retournent vers l'éleveur ou le bouvier en saisissant ses biens afin de l'obliger à payer. Une réaction qui conduit parfois à des tensions voire à des conflits. en ajout, la justice par l'équilibre des préjudices qui est le fait que les paysans « rendent les dégâts par les dégâts». Les paysans ont eu l'expérience de plusieurs cas de dégâts non dédommagés sinon le montant perçu ne reflétait pas la valeur des dégâts. Les paysans décident de se faire justice en procédant par l'équilibre des préjudices où un dégât de culture se solde désormais par des abattages des animaux ou par la violence sur le bouvier. C'est ce principe qui a été appliqué dans le village de Yérétiélé où 109 bœufs ont été tués. Souvent, ce sont les bouviers qui conduisent volontairement les bœufs dans les champs pour exprimer leur mécontentement à l'égard de leur employeur.

Les conflits liés au manquement des normes sociales

Quant aux conflits relevant au manquement des normes sociales, le cas de conflit relevé porte sur le fait que souvent les bouviers ou les éleveurs courtisent les femmes ou les jeunes filles déjà fiancées à des autochtones. Une pratique qui n’est pas appréciée par les autochtones.

" Ils vont détruire ton champ et coucher avec ta femme, si cela peut plaire aux autorités, en tout cas, on peut pardonner les dégâts dans les champs mais au village ah, si les autorités ont pu trouver une solution à ça, vraiment je serai étonné en toute vérité au nom de Dieu » (Extrait d'entretien réalisé avec SK le 11 Avril 2012 à Tchinvolokaha Dianra S/P).

\section{Les enjeux de l'exploitation des ressources agropastorales}

Dans l'espace agropastoral de Dianra, l'accès aux ressources pastorales comporte des enjeux importants compte tenu de l'évolution du contexte socioéconomique et environnemental. Il s'agit d'enjeux productifs, économiques, politiques et symboliques inscrits dans le cours terme ou dans 
la longue durée. En effet, la réduction du pâturage et des parcours de bétail compromet la mobilité des troupeaux et leur accès aux ressources. Or, la mobilité des troupeaux, l'utilisation des ressources naturelles communes, l'accès à une diversité de ressources et la réciprocité d'accès aux ressources, constituent les principes sur lesquels repose l'activité pastorale. Du coup, les sources de revenu ou les moyens de subsistance de l'éleveur sont menacés. Par ailleurs, l'activité agricole est aussi menacée. En effet, en absence de terrains de parcours et de pâturage, les champs de cultures deviennent ainsi les lieux de pâturages et de parcours des troupeaux entraînant des dégâts incessants de cultures. Les dégâts de cultures, les conflits entre agriculteurs et éleveurs conjugués aux effets de la variabilité climatique, créent une situation d'insécurité (les moyens de subsistance menacés ainsi que les personnes). Cette situation engendre en conséquence un sentiment de frustration chez les populations. Elles accusent les éleveurs de prendre «leur richesse» détruire les leurs. Eux, propriétaires terriens, ont un sentiment de perte d'autorité sur leur propre terre, et même la perte de leur identité d'autochtone. Nous notons ici que l'accès aux ressources agropastorales regorge d'enjeux divers relatifs aux groupes d'utilisateurs. Il s'agit d'enjeux productifs, économiques, rentiers, politiques et symboliques inscrits dans le cours terme ou dans la longue durée.

Face à ces enjeux, nous avons relevé des pratiques et des interactions chez les acteurs de l'espace agropastoral de Dianra que traite la partie suivante.

\section{Stratégies d'interactions des groupes d'utilisateurs des ressources Les pratiques des populations autochtones}

L'activité de l'élevage dans l'espace agropastoral de Dianra engendre une situation d'insécurité que vivent les populations : insécurité des biens (agricoles) liée aux dégâts de culture, insécurité des personnes liée aux conflits souvent soldés par des coups et blessures et, même insécurité du droit d'usage des populations. Cette situation constitue une nouvelle donne pour ces populations qui n'utilisaient autrefois ces ressources que pour l'activité agricole. Mais, les populations autochtones ne subissent pas passivement cette situation. Elles adoptent des stratégies dont des stratégies de protection ou de contrôle. Parmi celles-ci, nous notons la modification des règles du jeu. Les populations procèdent par la modification des règles du jeu qui se traduit par la mise en place des conditions d'accès aux ressources, la suppression du tutorat concernant les migrants éleveurs et la dissolution du comité villageois des aînés sociaux.

$\checkmark$ Mise en place des conditions d'accès aux ressources

L'instauration des conditions d'accès aux ressources pastorales entraîne le passage d'un accès gratuit ou libre à un accès de plus en plus 
contrôlé ou régulé. Les populations exercent désormais un contrôle sur l'accès des migrants éleveurs aux ressources pastorales. Dorénavant, les migrants éleveurs doivent avoir la permission de certains acteurs clés de l'arène politique villageoise dont les chefs de village, les propriétaires terriens ainsi que les jeunes ou groupes de jeunes constituant les nouveaux acteurs du dispositif local de régulation de l'accès aux ressources. Les jeunes, cette catégorie sociale s'est construit une place dans la régulation de l'accès aux ressources. Dans certains terroirs, les jeunes se sont constitués en association et interviennent dans la régulation de l'accès aux ressources. Ils constituent ainsi une autorité à part entière. Le chef du village ou le propriétaire terrien s'il l'un ou l'autre accepte l'éleveur, il doit dire «aux jeunes que bon telle personne est dans ma terre il m'a vu on est d'accord il est à côté de moi. Si vous le voyez puisque c'est moi qui l'ai mis là bas ». Les jeunes sont devenus une catégorie d'acteurs incontournable dans la régulation de l'accès aux ressources.

En outre, l'une des conditions est le paiement d'une redevance (nature ou espèce). En effet, l'accès des migrants éleveurs aux ressources pastorales n'est plus gratuit. Il est payant soit en nature ou en espèce selon les terroirs, le chef du village ou le propriétaire terrien. En effet, une somme d’argent est exigée aux éleveurs désirant séjourner dans un terroir par le chef du village, le propriétaire terrien et même les jeunes. Cette somme n'est pas fixe. Elle est négociée.

"Je suis parti à gbinmlinso ils m'ont demandé de payer un bœuf j'ai refusé je les ai pardonné, après ils m'ont dit de payer 50 000. Je les ai pardonné aussi. C'est devenu discussion entre nous, après j'ai payé. Parce que j'ai trouvé que avec un mois je vais donner 50000 frcs en tout cas ça ne m'arrange pas ». (Extrait de l'entretien réalisé avec S.M, éleveur, le 29/11/2012 à Dianra $S P$ ).

Mais, dans la majorité des cas, les chefs de village ou les propriétaires terriens demandent des bœufs. Le fait qu’ils préfèrent le bœuf n'est pas fortuit. Il faut dire qu'avec l'adoption de la culture attelée, il y a un besoin manifeste en bœuf de culture. Ces bœufs de culture constituent chez les populations une force de travail importante dans la production agricole. Dans le passé, l'éleveur donne un bœuf en guise de reconnaissance et n'est pas obligatoire. Et ce bœuf apparaît comme un présent. Mais, aujourd'hui, il devient une obligation et prend le nom de redevance. En saison sèche, l'accès à l'eau du barrage est payant. Les populations demandent 1000frcs Cfa par troupeau de bœufs. C'est le cas à Yérétiélé, village où se trouve un barrage. Les migrants agropasteurs n’échappent pas au payement du droit d'usage des ressources pastorales. En effet, les agropasteurs sont des personnes qui pratiquent les deux activités (agriculture et l'élevage). Ils demandent la terre aux autochtones propriétaires terriens pour l'activité 
agricole. Mais, ayant des bœufs, ils construisent leurs parcs sur les terres qui leur sont octroyées. Bien même que la terre qu'ils occupent leur a été donnée, ils doivent payer une redevance ou le droit d'usage des ressources pastorales pour les bœufs.

Enfin, l'une des règles est la responsabilisation de l'éleveur. La responsabilité de l'éleveur est l'une des conditions pour que l'éleveur obtienne l'autorisation de s'installer dans une zone. Cette convention stipule que tous les champs situés dans le périmètre où se trouve l'éleveur ou le bouvier, sont sous la responsabilité de celui-ci. C'est-à-dire en cas de dégâts de culture dans la zone, l'éleveur doit «trouver la personne qui a fait le dégât ». Au cas où il ne retrouverait l'auteur, c'est cet éleveur reconnu par les autorités villageoises comme celui qui "paye le champ». Cette convention résulte en effet, du fait que des dégâts de cultures sont restés non indemnisés parce qu'on n’a pas retrouvé ou identifié les auteurs.

Après avoir fait évoluer les conditions d'accès aux ressources, les populations autochtones procèdent aussi à la suppression du tutorat concernant les migrants éleveurs.

$\checkmark$ la suppression du tutorat concernant les migrants éleveurs

Selon Chauveau (2004: 3), "La relation du "tutorat foncier" correspond à une institution agraire générale aux sociétés paysannes africaines. Elle s'insère dans le dispositif normatif caractéristique d'une économie morale dans laquelle il existe un consensus sur le fait que le déroulement des processus économiques ne doit pas remettre en cause l'accès de tout individu, même étranger à la communauté, aux moyens de subsistance pour lui et sa famille - à charge pour l'étranger de respecter un "devoir de reconnaissance" à l'égard de son tuteur et de la communauté d'accueil, dans la perspective de son intégration plus ou moins explicitement recherchée et plus ou moins complète dans la communauté hôte. ».

L'institution du tutorat en milieu rural africain, joue un rôle fondamental dans la gestion de la mobilité au sens où elle comporte quatre dimensions essentielles: morale, sociale, économique et identitaire. Au niveau moral, le tutorat s'inscrit dans le principe de l'économie morale qui fait de l'accueil de l'étranger un devoir moral du groupe ou de la société d'accueil : " On ne refuse pas la terre à un étranger. " Au niveau socioéconomique, le tutorat permet un transfert temporaire ou définitif de droits d'exploitation à des étrangers. C'est cette dimension qui permet à ces derniers d'avoir accès aux ressources dans les zones d'accueil. Enfin, la dimension identitaire fait du tutorat un instrument social visant une intégration parfaite des étrangers dans leur communauté d'accueil (Bologo, 2004). Il s'agit alors d'une convention sociale destinée à régler les relations avec des « étrangers »en déléguant des droits d'usages ou d'occupation d'un terroir ( Babo et Droz, 2008:746). 
Dans l'espace agropastoral de Dianra, les éleveurs ou les bouviers migrants bénéficient ou ont bénéficié des bienfaits du tutorat ou de ce devoir moral dans les terroirs d'accueil. À travers le tutorat, tout se passe comme s'il existait un droit naturel d'accès aux ressources, le droit qu'a chaque homme, qu'il appartienne à la communauté villageoise ou qu'il en soit étranger, de se faire attribuer un droit d'accès aux ressources pour assurer sa subsistance. En effet, lorsqu'un éleveur ou un bouvier arrive dans un terroir, il se cherche un tuteur. Car, il est nécessaire d'avoir un tuteur dont on peut bénéficier de son hospitalité (la cuisine, l’hébergement...) et de son soutien pour avoir accès aux ressources. Il peut s'installer ou séjourner dans ce terroir à durée déterminée ou non. Le tuteur a l'obligation de l'informer des règles de conduite à observer en relation avec l'activité de l'élevage et de son statut d'étranger. À cet effet, le tuteur est souvent responsable vis à vis des autres autochtones des faits et gestes de son étranger par rapport aux règles et normes sociales locales. Le tutorat permet ainsi aux éleveurs d'avoir un droit d'accès plus ou moins garanti aux ressources pastorales (pâturage, eau) et aussi de pouvoir saisir le bouvier ou l'éleveur en cas de dégât de culture. Ainsi, lorsque le dégât survient, le tuteur joue le rôle de médiateur. L'institution tutorat constitue donc un cadre de construction sociale de la coopération entre des groupes sociaux. Le tutorat offre donc un cadre légal pour l'accueil des migrants étrangers.

Mais, depuis lors, les codes qui fondent la relation de tutorat se sont effondrés ou s'effondrent en raison des nombreux conflits dont la plupart est liée aux dégâts de cultures. En conséquence, il y a eu une reconsidération des relations. Celle-ci a conduit à une suppression progressive de l'institution tutorat dans des terroirs. C'est-à-dire il est interdit aux habitants du village d'être tuteur d'un éleveur ou d'un bouvier. Le tutorat qui fait que l'autre accueillait par hospitalité n'existe plus. La suppression du tutorat est donc une mesure de sécurité et un indicateur du climat social qui caractérise les relations autochtones et migrants éleveurs.

Elle révèle la mutation de certaines valeurs sociales en cours dans ce milieu. En effet, le tutorat est une institution prônant des valeurs comme la solidarité et l'hospitalité qui ont toujours prévalu dans nos sociétés africaines (rurales) surtout dans l'accès aux ressources. C'est la solidarité des populations d'accueil aux migrants à la recherche de ressources pour leur subsistance. Le tutorat permet donc l'intégration sociale. En analyse, la suppression de l'institution tutorat marque la fin du devoir moral que constitue l'accueil d'un étranger et de lui permettre d'accéder aux ressources ou au moyen de subsistance. La suppression du tutorat et la marchandisation de l'accès aux ressources révèlent une transformation de valeurs dans l'accès des migrants aux ressources. Nous passons de la solidarité, de l'hospitalité et de l'interdépendance entre agriculteurs et éleveurs, au commerce et aux 
business. En d'autres termes, nous assistons à une mutation des valeurs de société en valeurs de la société de marché. La culture mercantile (comme l'anacarde par exemple) a pris le dessus sur la question de solidarité. En d'autres situations, l’on parlerait de « crise de valeurs ». Rahma (2010 : 109), dans une étude au Maroc, révèle que la mutation des valeurs est le fait du changement social. En effet, selon lui, la colonisation, la migration, les médias de la globalisation, la mondialisation et la modernité, ont engendré des conflits autour des valeurs, ou « la crise des valeurs ».

Mais, au-delà des modifications de l'environnement, le passage de plus en plus des sociétés traditionnelles à des sociétés modernes participent aussi au changement en cours dans les relations sociales autour des ressources agropastorales. Les individus qui se "ressemblent » ou qui sont tous les même et partagent les mêmes valeurs dans les sociétés dites traditionnelles, se différencient dans les sociétés dites modernes où les normes et les valeurs deviennent de moins en moins contraignantes, et où la conscience individuelle prime sur la conscience collective. A Dianra, nous avons aujourd'hui une population d'agriculteurs de plus en plus jeunes aux repères culturels divers. D'ailleurs, ceux-ci revendiquent auprès des aînés sociaux, leur place dans les centres de prise de décisions concernant la gestion des ressources. Ils possèdent donc différentes manières de faire et de savoir faire. En effet, les populations cherchant les solutions aux problèmes auxquels elles sont confrontées, adoptent de nouvelles pratiques. Toutefois, cette mutation n'est sans conséquences sur l'accès aux ressources et met en mal le principe de l'économie morale.

\section{$\checkmark$ L'usage du «bâton d'argent »}

Selon les autochtones, si les éleveurs refusent de partir de leur terroir, seul le "bâton de l'argent » pourrait les contraindre à partir. En effet, à défaut de chasser ouvertement les éleveurs (défendu par l'État) les dégâts de culture deviennent une opportunité que se saisissent les autochtones en utilisant la stratégie du "bâton de l'argent ». Utiliser le "bâton d'argent », revient à augmenter le montant d'indemnisation en cas de dégâts. Ainsi, l'un des constats faits par les éleveurs ou tout acteur impliqué dans le règlement des différends, c'est l'augmentation abusive des frais d'indemnisations après les dégâts de culture. C'est-à-dire le paysan ou le comité demande une somme ne reflétant pas la valeur réelle des dégâts.

$\checkmark$ la dissolution des comités villageois des aînés sociaux

Les comités villageois installés par le sous préfet, ont été dissouts par les jeunes. Ces comités étaient dirigés par les aînés sociaux. En effet, les sous préfets, compte tenu des conflits récurrents dans le département de Dianra, ont installé des comités villageois de règlement de différends entre les paysans et les éleveurs. Le comité aide en quelque sorte le sous préfet dans sa tâche en intervenant en premier lieu entre les deux protagonistes. Mais, 
ceux-ci ont été dissouts par les jeunes autochtones pour en faire émerger d'autres comités exerçant sous leur contrôle. Les aînés sont accusés par les jeunes de faire le jeu des éleveurs ou d'être trop impartiale. Cette dissolution répond à une stratégie de contrôle du processus de règlement des différends et répond à des logiques propres aux cadets sociaux. Le contrôle des comités par les jeunes s'est suivi de nouvelles règles régissant le règlement des différends. Ces nouvelles règles se présentent comme suit :

-La construction des parcs à fourrière servant à garder ou enfermer les bœufs auteurs des dégâts,

-Le paiement par le propriétaire des droits de parc qui a servi à garder ses bœufs des bœufs,

-Le paiement des droits des dozo ayant surveillé les bœufs dans les parcs. Parfois, les dozo sont ceux-là qui vont chercher les bœufs dans la brousse en cas de dégâts de cultures et les conduire dans les " graba » ou parc à fourrière. Le droit des dozo est fixé par jour ou par le nombre de nuit passé dans le parc.

-«tu ne paye pas on libère pas tes bœufs». Avec le comité des jeunes, les éleveurs sont confrontés au principe de «Si tu ne paye pas on libère pas tes bœufs ». Après plusieurs expériences déçues (non indemnisation des dégâts causés ou somme non satisfaisante), la libération des bœufs mis dans le parc à fourrière est conditionnée par le paiement immédiat et obligatoire des frais d'indemnisation. Nos résultats sont soutenus par plusieurs travaux attestant que dans un contexte marqué par une insécurité juridique structurelle et une certaine indétermination du jeu foncier, les acteurs stabilisent des « itinéraires de sécurisation » dans la façon de mobiliser les différents pouvoirs, coutumiers, administratifs, et autres (Blundo, 1996 ; Jacob, 2002 ; Mathieu et al (2002). Chaque acteur ou groupe d'acteurs, au gré de ses intérêts personnels, prend dans les différents registres à sa disposition, les éléments qui vont lui permettre de tirer son épie du jeu

\section{Les pratiques des éleveurs}

Les éleveurs, quant à eux, adoptent des stratégies d’accès. Ces stratégies se présentent comme suit :

a) les formes d’arrangement: développement de système de prêt de boufs de culture

Dans un contexte marqué par les conflits où les populations deviennent de plus en plus hostiles aux bœufs, les éleveurs procèdent par des arrangements. En effet, pendant la période des activités agricoles, pour bénéficier d'un accès plus ou moins sécurisé ou garanti aux ressources, la stratégie des éleveurs est de prêter gratuitement des têtes de bœufs aux paysans pour effectuer leurs activités agricoles. En mettant ses bœufs à la disposition des paysans, l'éleveur cherche à tirer un double bénéfice : avoir 
un accès garanti aux ressources et aussi recevoir la protection des paysans ayant reçu la main d'œuvre animale lorsqu'ils seront en cas de conflit. Cet arrangement et ou cette convention répond à une mesure d'adaptation à la précarité d'accès aux ressources ainsi qu'à la situation conflictuelle. Le besoin en bœufs de culture apparaît en effet comme une opportunité ou une marge de manœuvre à exploiter pour les éleveurs. L’absence de main d'œuvre manuelle due à l'adoption de la traction animale a constitué un handicap dans la production agricole. Car, nombreux sont les familles qui ne disposent pas de bœufs de culture. Selon les populations interrogées, même si ceux qui en possèdent, mettent les siens en location, il faut aussi avoir les moyens financiers pour s'offrir le service. Alors, les incertitudes quant à l'accès à une main d'œuvre agricole sont grandes. Dans cette situation d'incertitude, l’offre de l'éleveur apparaît comme une solution.

b) la manipulation du référent identitaire professionnel : se faire passer pour un agro éleveur

L'hostilité des populations aux bœufs amènent certains éleveurs à pratiquer aussi l'agriculture ou à faire aussi des champs. Car, il n'est plus facile pour les éleveurs d'obtenir auprès des villageois un espace ou une portion de terre pouvant exclusivement servir de pâturage. En fait, dans l'idéologie des populations, si l'éleveur est aussi agriculteur, il ne peut pas prendre ses bœufs pour détruire leurs cultures. Ils se reconnaissent en celui-ci comme un des leurs. C’est cette idéologie qui est exploitée par certains éleveurs pour avoir accès aux ressources en manipulant leur identité professionnelle. Ainsi, l’identité professionnelle « agriculteur » devient donc un moyen dont usent les éleveurs pour avoir accès aux ressources. Le référent identitaire professionnel joue ici un rôle important dans l'accès aux ressources et même à l'intégration des migrants éleveurs. C'est donc une stratégie adoptée par nécessité ou par contrainte pour s'adapter à un contexte de conflits et d'incertitudes résultant d'un environnement marqué par l'amenuisement des ressources.

c) «s'associer » : la recherche d'une force collective

Les éleveurs, face aux difficultés se sont organisés en association. Les éleveurs ont compris que pour mieux défendre leurs intérêts, il faut qu'ils s'unissent. Ainsi, les éleveurs sédentaires ont mis en place l'Association des Eleveurs de Bétails et de Volailles de Dianra (A.E.B.V.D).

Donnant les raisons de la naissance de leur association, cet éleveur affirme ceci :

«Nous les éleveurs de Dianra, monsieur Kouamé on a trop de problèmes. Voilà pourquoi on a cherché à s'associer un peu pour faire un bureau. Si on s'associe pour faire un petit bureau pour qu'on arrive à se défendre, pour savoir défendre nos biens qui sont 
dans nos mains » (Extrait d'entretien réalisé avec S M, éleveur, le 29/11/2012 à Dianra S/P).

Par cette association, les éleveurs recherchent la sécurisation de leur activité par un accès durable aux ressources. Agir ensemble ou en une force collective devient donc une stratégie dont de pouvoir dans ce contexte conflictuel. À Dianra Sous préfecture, l'association a entamé des protestations silencieuses auprès des autorités traditionnelles telles que le chef canton. Cette action visait à obtenir une cohabitation pacifique entre populations autochtones et migrants éleveurs.

d)

La manipulation des faits: le jeu de discours

Les éleveurs, engagés dans un jeu, exploitent toute situation pouvant leur permettre d'avoir les termes de l'échange à leur faveur. Ainsi, ils brandissent l'argument de perte d'animaux lorsque leurs bœufs sont conduits dans les parcs à fourrière et, accusent souvent les populations d'agression pour sortir « leur épingle du jeu ». En effet, lorsque les bœufs d'un éleveur ont commis des dégâts, celui-ci adopte des stratégies afin de ne pas indemniser le paysan ou d'obtenir une indemnisation réciproque des préjudices. En réponse à la stratégie de mise en parc des bœufs, les éleveurs ont trouvé une autre stratégie, celle de disparition inventée de leurs animaux. En fait, lorsque les bœufs d'un éleveur sont mis dans le parc à fourrière par les populations, celui-ci après avoir indemnisé le paysan, déclare la disparition de quelques têtes de ses bœufs. En d'autres termes, il affirme ne pas retrouver la totalité de ses bœufs. Partant, les paysans ayant enfermé les bœufs, sont rendus coupables de perte d'animaux. Ils sont ainsi amenés à indemniser l'éleveur à un montant très élevé que celui des dégâts de culture. L'éleveur contrôle une zone d'incertitude relative à l'effectif exact de ses animaux car, il est le seul à le connaître. En outre, les éleveurs connaissant la réaction des agriculteurs suite aux dégâts de culture, ont développé une autre stratégie. Il s'agit d'accuser les agriculteurs d'agression afin de les incriminer. Généralement, l'agression est lourdement sanctionnée plus que les dégâts. Par exemple, à Solifiro, un bouvier dans sa fuite après un dégât commis par ses bœufs dans un champ d'anacardier, est tombé et s'est blessé au front. Partant, les éleveurs ont saisi le Sous préfet et ont demandé que le paysan paye une somme de 100000 francs CFA comme frais de soin du bouvier. Selon les éleveurs, ce dernier a été agressé et il y a eu coup et blessure. Le paysan a payé cette somme sans que son champ ne soit en retour indemnisé par les éleveurs. Comme le disent Crozier et friedberg (1977), les stratégies ne dépendent pas d'objectifs claires, mais elles se construisent en situation en fonction des atouts que peuvent avoir les acteurs et aux relations dans lesquelles ils s'insèrent. 


\section{Conclusion}

La présente étude part de la question que comment les groupes d'utilisateurs (agriculteurs autochtones et migrants éleveurs) parviennent-ils à assurer leur accès aux ressources dans un contexte marqué par des conflits? Les analyses faites montrent que les acteurs développent un certains nombre de stratégies : des stratégies de contrôle et de maintien de l'accès aux ressources traduisant leur réponse au nouveau contexte environnemental. Nous relevons ainsi la modification ou le changement des règles du jeu à partir d'une fragilisation ou d'une mise en dynamique des institutions et, la pluralité de recours caractérisée par l’instrumentalisation de ces institutions chez les populations autochtones. Chez les migrants éleveurs, nous observons des formes d'arrangement par le système de prêt de bœufs de culture, des formes d'action collective et la manipulation du référent identitaire professionnel et celle des faits. Au cœur de ces stratégies, il y a une dimension institutionnelle: l'usage des institutions comme ressources (moyen de recours) pour configurer leurs stratégies ou pour se donner du pouvoir. Les acteurs s'adonnent en fait à des jeux de pouvoir aboutissant à la mutation de valeurs sociales dans l'accès aux ressources. Cependant, ces stratégies sont susceptibles de porter des conflits. La régulation locale de l'accès aux ressources dans un contexte de conflit d'usage des ressources qui elles-mêmes s'amenuisent, doit être prise en compte dans la recherche des solutions durables aux conflits liés à l'accès aux ressources. Il s’agit de lier le local au global.

\section{References:}

Babo Alfred et Droz Yvan. 2008, "Conflits fonciers de l'ethnie à la nation", Cahiers d'Études africaines XLVIII (4):pp. 741-763.

Béchir, Ibrahima Ali 2010. "Productivité, dynamique des parcours et pratique d'élevage bovin en zone saoudienne du Tcahd ", Thèse Université Polytechnique de Bobo - Dioulasso, Bobo-Dioulasso.

Blundo Giorgio, 1996, "Gérer les conflits fonciers au Sénégal : le rôle de l'administration locale dans le sud-est du bassin arachidier" dans L. Mathieu and Willame, Démocratie, enjeux fonciers et pratiques locales en Afrique, conflits, gouvernance et turbulences en Afrique de l'Ouest et centrale, CEDAF/L'Harmattan, Paris : 101-119

Bologo Eric, 2004, Populations rurales, mobilité et accès aux ressources foncières dans l'Ouest du Burkina Faso, Actes du Colloque du CEPED, 274 Peuplement, urbanisation, mobilité et environnement, 16-17Novembre 2004 Nogent-Sur-Mame, 30p

Chauveau Jean-Pierre, 2004, Conflit, crise de la ruralité et crise foncière en Côte d'Ivoire forestière: le "tutorat" entre autochtones et migrants au centre 
des 276 tensions, Atelier CLAIMS sur « foncier rural en Afrique »,21-24 Juin 2004, Bamako, 13p

Crozier Michel Erhard Friedberg, 1977, L'acteur et le système: les contraintes de l'action collective, Editions du Seuil, Paris, 509p

Friedberg Erhard. 1993. Le Pouvoir et la Règle: Dynamiques de l'action Organisée

Jacob Jean-Pierre, 2002, La tradition du pluralisme institutionnel dans les conflits fonciers entre autochtones. Le cas du Gwendégué (Centre-Ouest du Burkina Faso), Document de travail de l'UR (95), 39 p

Mathieu Paul, Philippe Lavigne Delville, Lacinan Paré, Mahamadou Zongo, Hubert Ouédraogo, 2002, Sécuriser les transactions foncières dans l'ouest du Burkina Faso, Dossier n¹17, IIED, Paris, 36p

Pires Alvaro, 1997, "Echantillonnage et recherche qualitative : essai théorique et méthodologique," dans J. Poupart, Deslauriers, Groulx, Laperrière, Mayer et Pires, La recherche qualitative. Enjeux épistémologiques et méthodologiques, Gaëtan Morin, Boucheville: 113-169 Rahma Bourqia, 2010, "Valeurs et changement social au Maroc", Quaderns de la Mediterrània, (13) :105-115 